\title{
The effect of adding morphine to intratecal bupivacaine on postoperative analgesia in patients with anorectal surgery
}

\author{
(D)Münire Babayiğit \\ University of Healh Science, Kecioren Training and Research Hospital, Anesthesiology and Reanimation Department, Ankara, Turkey
}

Cite this article as: Babayigit $\mathrm{M}$. The effect of adding morphine to intratecal bupivacaine on postoperative analgesia in patients with anorectal surgery. Anatolian Curr Med J 2021; 3(2); 124-129.

\begin{abstract}
Aim: Pain is the major problem in early postoperative period after anorectal operations. In this study, we aimed to evaluate the first analgesic requirement time and complications of intrathecal $5 \mathrm{mg}$ hyperbaric bupivacaine, intrathecal $5 \mathrm{mg}$ hyperbaric bupivacaine with intrathecal $50 \mu \mathrm{g}$ and $100 \mu \mathrm{g}$ of morphine combinations in anorectal surgery.

Material and Method: A total of 60 patients divided into 3 groups, including 20 patients in each group, were included for the study;Group 1: $5 \mathrm{mg}$ 0.5\% heavy bupivacaine (HB), Group 2: $5 \mathrm{mg} \mathrm{0.5 \%} \mathrm{HB}$ and $50 \mu \mathrm{g}$ Morphine, Group 3: $5 \mathrm{mg} 0.5 \% \mathrm{HB}$ and $100 \mu \mathrm{g}$ Morphine was intrathecally administered. Intraoperative and postoperative hemodynamics, time to urination and first analgesia requirement, perioperative and postoperative side effects were recorded

Results: The time to first analgesic requirement in Group $1(305.40 \pm 143.86)$ was statistically significantly lower than Group $2(435.50 \pm 171.70)$ and Group $3(435.50 \pm 156.08)(\mathrm{p}=0.015)$. No significant difference was found between urinary retention ( $>0.05)$. It was determined that the postoperative nausea and vomiting percentages $(25.0 \%)$ in Group 3 were statistically significantly higher than Group $2(5.0 \%)$ and Group $1(0.0 \%)(\mathrm{p}<0.05)$.

Conclusions: The use of $50 \mu \mathrm{g}$ of intrathecal morphine in patients undergoing anorectal surgery in saddle block anesthesia has the expected effect on postoperative analgesia and for this reason it is considered appropriate to be preferred in anorectal surgery thus to the minimal adverse side effects.
\end{abstract}

Keywords: Anorectal surgery, pain, bupivacaine, intratechal, morphine

\section{INTRODUCTION}

While $41 \%$ of the patients complained of severe or moderate pain on the first day after surgical interventions, more than half of the patients felt more pain than they expected in the early postoperative period after anorectal surgery $(1,2)$. Therefore, in perianal operations, it is important to provide effective analgesia during the early postoperative period as well as during the operation.

Perianal operations performed for benign anal pathologies are short-term procedures and patients are usually discharged the next day. Therefore, neuraxial blocks, especially saddle spinal anesthesia is the safest and most preferred method in anesthesia management. Saddle block was found to be more effective than lumbar epidural or caudal block for depressing anal sphincter tone (3).In saddle spinal anesthesia, it is preferred to use low-dose, short-acting local anesthetic agents together with opioids to avoid motor block and provide adequate surgical anesthesia. Intrathecal addition of morphine to local anesthetics during spinal anesthesia also provided effective postoperative analgesia after a series of surgical procedures $(4,5)$.

Morphine is preferred because of its long duration of action and its long postoperative analgesic effect (6). However, side effects such as nausea, vomiting, itching, fatigue, urinary retention, delayed respiratory depression and sedation are seen at various rates depending on the dose and disrupt patient comfort (7). Therefore, the lowest morphine dose with the incidence of side effects becomes important while providing effective analgesia.

In this study, we aimed to evaluate the effect of adding $50 \mu \mathrm{g}$ or $100 \mu \mathrm{g}$ of morphine (Morphine HCL) on intrathecal $5 \mathrm{mg}$ hyperbaric bupivacaine (Bustesin spinal heavy $0.5 \%$ ) on postoperative analgesia before anorectal surgery. 


\section{MATERIAL AND METHOD}

The study protocol was approved by the Ethics Committee of the Keçiören Training and Research Hospital (date/ approval number: 27.08.2014/651). The trial was conducted in accordance with the Helsinki Declaration principles and all volunteers provided written informed consent.

American Society of Anesthesiologists (ASA) physical status I-II and patients over the age of 18 who were scheduled for anorectal surgery in our hospital were included in the study. Patients who did not accept regional anesthesia, ASA III-IV and patients who have coronary artery disease, hypertension, heart failure, arterial aneurysm, epilepsy, intracranial mass, liver failure, renal failure, abnormal coagulation profile, patients who were constantly using narcotic analgesics and allergic to study drugs were excluded from the study. The patients were divided into 3 groups using the closed envelope technique. The study was planned as double blind, and anesthesia application and intraoperative and postoperative patient follow-up were performed by different researchers. Following standard monitoring, saddle spinal anesthesia technique was applied with a 25 gauge spinal needle with a midline approach from the L3-4 interval in the sitting position. The patients were kept in this position for 5 min to achieve sufficient block. Sensory block was evaluated by the pin-prick method until sufficient block reached the S4 level. Motor block was evaluated according to a modified Bromage scale.

A total of 60 patients, including 20 patients in each group, were included for the study;

- Group 1: $5 \mathrm{mg}$ 0.5\% heavy bupivacaine (HB),

- Group 2: $5 \mathrm{mg}$ 0.5\% HB and $50 \mu \mathrm{g}$ Morphine,

- Group 3: $5 \mathrm{mg}$ 0.5\% HB and $100 \mu \mathrm{g}$ Morphine was intrathecally administered.

The patient, the anesthesiologist performing the saddle block, the anesthesiologist who followed the peroperative and postoperative patients and the surgeon were blind to the study.

Intramuscular $75 \mathrm{mg}$ diclofenac sodium was administered when additional analgesic was required in the postoperative period.

Age, gender, height, body weight of patients during preoperative evaluation, intraoperative 1-10-20-30-4060. systolic arterial pressure per minute, diastolic arterial pressure, mean arterial pressure (MAP), heart rate (HR), additional drug use and amounts were recorded. Spinal anesthesia time, surgery initiation time, and surgical ending time were recorded. Time to urination and first analgesia requirement were evaluated and recorded. Perioperative and postoperative side effects; Sedation, respiratory depression, nausea, vomiting, motor block and urinary retention were recorded.

\section{Statistical Analysis}

Expressions such as mean \pm standard deviation and median ( $\min -\max )$ were used for continuous variables, and numbers and percentages were used for categorical data. In the intergroup analysis of continuous variables, normality analyzes were performed using the Kolmogorov-Smirnov Goodness of Fit Test. In the analyzes between the three groups, the Oneway ANOVA (Post hoc: LSD) Test was used in cases where the variables fit the normal distribution, and the Kruskal Wallis Test (Mann Whitney U Test for further analysis) was used when it did not. Friedman Test was used for analysis between dependent groups, and comparison of categorical data was made using ChiSquare Test. The Pearson Correlation coefficient was used to determine the linear relationship (correlation) between variables. Analyzes were done with IBM SPSS Package Program version 24.0 (IBM Corporation, Armonk, NY, USA). Statistical significance level was taken as $\mathrm{p}<0.05$.

\section{RESULTS}

No statistically significant difference was found between the groups in terms of age, gender, body mass index (BMI), mean operation time, ASA, type of surgery performed and position ( $\mathrm{p}>0.05$, Table 1$)$.

Generally, Group 1 peroperative heart rate values were found to be lower than Group 2 and Group 3. While Group 3 beginning (0th minute) heart rate values $(87.85 \pm 10.53)$ were significantly higher than Group 1 (78.95 \pm 11.63$)$, it was determined that the 15 th minute peroperative heart rate values were significantly higher in Group $2(81.50 \pm 12.93)$ compared to Group $1 \quad(73.15 \pm 9.33) \quad(\mathrm{p}<0.05)$. The peroperative heart rate levels ( $0-45$ minutes) within the groups were not statistically significant $(\mathrm{p}>0.05)$. There was no significant difference in MAP values between the groups (Table 2).

The $6^{\text {th }}$ hour HR values in Group $2(81.65 \pm 9.42)$ were significantly higher than Group 3 (73.55 \pm 8.70$)$. In addition, it was determined that the $24^{\text {th }}$ hour MAP values were significantly higher in Group 3 (91.53 \pm 6.53$)$ compared to Group $1(85.79 \pm 5.76)$ $(\mathrm{p}<0.05)$. The postoperative HR levels (1-24 hours) within the groups made a significant difference in Group 3. In terms of HR values in Group 3, the 12th and $24^{\text {th }}$ hour values increased significantly compared to the 1 st to 6 th hours $(\mathrm{p}<0.05$, Table 3$)$.

It was determined that the postoperative nausea and vomiting percentages $(25.0 \%)$ in Group 3 were statistically significantly higher than Group 2 (5.0\%) and Group $1(0.0 \%)(\mathrm{p}<0.05)$. Sedation, respiratory 
depression, motor block was not developed in any patient, and no significant difference was found between the rates of headache, hypotension, bradycardia and urinary retention ( $p>0.05$, Table 4$)$.
The time to first analgesic requirement in Group 1 (305.40 \pm 143.86$)$ was statistically significantly lower than

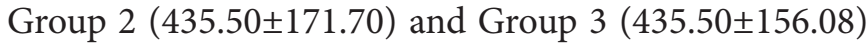
was determined ( $\mathrm{p}=0.015$, Table 5).

\begin{tabular}{|c|c|c|c|c|c|}
\hline & Group $1(n=20)$ & Group $2(n=20)$ & Group $3(n=20)$ & Total $(n=60)$ & $\mathbf{p}$ \\
\hline Age (years) (Mean $\pm \mathrm{SD})$ & $39.55 \pm 11.9$ & $38.60 \pm 12.78$ & $40.35 \pm 13.08$ & $39.50 \pm 12.39$ & $0.908^{\star}$ \\
\hline BMI $\left(\mathrm{kg} / \mathrm{m}^{2}\right)(\mathrm{Mean} \pm \mathrm{SD})$ & $26.63 \pm 4.99$ & $25.69 \pm 4.07$ & $27.12 \pm 2.70$ & $26.48 \pm 4.01$ & $0.526^{*}$ \\
\hline Operation time (min) $($ Mean \pm SD) & $27.60 \pm 8.27$ & $28.45 \pm 11.07$ & $32.80 \pm 11.16$ & $29.62 \pm 10.61$ & $0.255^{\star}$ \\
\hline Gender $(n, \%)$ & & & & & $0.918^{* *}$ \\
\hline Female & $6(30.0 \%)$ & $5(25.0 \%)$ & $5(25.0 \%)$ & $16(26.7 \%)$ & \\
\hline Male & $14(70.0 \%)$ & $15(75.0 \%)$ & $15(75.0 \%)$ & $44(73.3 \%)$ & \\
\hline ASA $(n, \%)$ & & & & & $0.415^{\star *}$ \\
\hline I & $13(65.0 \%)$ & $15(75.0 \%)$ & $11(55.0 \%)$ & $39(65.0 \%)$ & \\
\hline II & $7(35.0 \%)$ & $5(25.0 \%)$ & $9(45.0 \%)$ & $21(45.0 \%)$ & \\
\hline Operation type (n,\%) & & & & & $0.118^{\star *}$ \\
\hline Hemorrhoidectomy & $6(30.0 \%)$ & $1(5.0 \%)$ & $6(30.0 \%)$ & $13(21.7 \%)$ & \\
\hline Fistulotomy & $9(45.0 \%)$ & $8(40.0 \%)$ & $9(45.0 \%)$ & $26(43.3 \%)$ & \\
\hline Sphincterotomy & $5(25.0 \%)$ & $11(55.0 \%)$ & $5(25.0 \%)$ & $21(35.0 \%)$ & \\
\hline Position (n,\%) & & & & & $0.166^{* *}$ \\
\hline Jack knife & $11(55.0 \%)$ & $16(80.0 \%)$ & $11(55.0 \%)$ & $38(63.3 \%)$ & \\
\hline Lithotomy & $9(45.0 \%)$ & $4(20.0 \%)$ & $9(45.0 \%)$ & $22(36.7 \%)$ & \\
\hline Total & $68(100 \%)$ & $88(100 \%)$ & $88(100 \%)$ & $156(100 \%)$ & \\
\hline
\end{tabular}

Table 2. Comparison of the peroperative HR and MAP values of the groups

\begin{tabular}{|c|c|c|c|c|c|c|c|c|}
\hline & HR 0. min & HR 5. min & HR 10. min & HR 15. min & HR 20. min & HR 30. min & HR 45. min & $\mathbf{p}^{1}$ \\
\hline Group 1 & $78.95 \pm 11.63^{* *} \mathrm{a}$ & $76.05 \pm 11.59$ & $75.50 \pm 13.61$ & $73.85 \pm 11.55^{\star \star} \mathrm{a}$ & $73.15 \pm 9.33$ & $73.00 \pm 10.23$ & $75.00 \pm 6.37$ & $0.663^{*}$ \\
\hline Group 2 & $84.05 \pm 11.81$ & $82.45 \pm 12.13$ & $82.75 \pm 14.14$ & $81.65 \pm 11.20^{* *} \mathrm{a}$ & $81.50 \pm 12.93$ & $78.56 \pm 15.58$ & $85.75 \pm 12.71$ & $0.981^{*}$ \\
\hline \multirow[t]{3}{*}{ Group 3} & $87.85 \pm 10.53^{* *} a$ & $85.50 \pm 12.14$ & $82.10 \pm 10.74$ & $78.90 \pm 9.29$ & $78.75 \pm 9.22$ & $77.86 \pm 9.08$ & $78.86 \pm 7.96$ & $0.143^{*}$ \\
\hline & $\mathrm{p} 2=0.042^{\star *}$ & $\mathrm{p} 2=0.086^{\star *}$ & $\mathrm{p} 2=0.098^{\star *}$ & $\mathrm{p} 2=0.043^{* *}$ & $\mathrm{p} 2=0.061^{\star *}$ & $\mathrm{p} 2=0.473^{* *}$ & $\mathrm{p} 2=0.275^{\star *}$ & \\
\hline & MAP 0. min & MAP 5. min & MAP 10.min & MAP 15. $\mathrm{min}$ & MAP 20. min & MAP 30.min & MAP 45.min & \\
\hline Group 1 & $101.15 \pm 15.78$ & $97.25 \pm 22.22$ & $92.90 \pm 14.36$ & $90.60 \pm 17.20$ & $89.90 \pm 13.63$ & $92.09 \pm 14.18$ & $90.00 \pm 9.79$ & $0.528^{*}$ \\
\hline Group 2 & $99.40 \pm 16.76$ & $91.45 \pm 23.69$ & $90.30 \pm 8.46$ & $93.50 \pm 8.18$ & $90.18 \pm 7.06$ & $91.09 \pm 9.04$ & $91.00 \pm 4.69$ & $0.461^{*}$ \\
\hline \multirow[t]{2}{*}{ Group 3} & $103.45 \pm 12.70$ & $90.65 \pm 22.59$ & $93.30 \pm 6.64$ & $91.70 \pm 8.41$ & $90.25 \pm 7.94$ & $90.71 \pm 6.79$ & $89.29 \pm 1.25$ & $0.253^{*}$ \\
\hline & $\mathrm{p} 2=0.640^{\star *}$ & $\mathrm{p} 2=0.972^{\star *}$ & $\mathrm{p} 2=0.443^{\star *}$ & $\mathrm{p} 2=0.199^{* *}$ & $\mathrm{p} 2=0.718^{\star *}$ & $\mathrm{p} 2=0.571^{\star *}$ & $\mathrm{p} 2=0.888^{\star *}$ & \\
\hline
\end{tabular}

Table 3. Comparison of the postoperative HR and MAP values of the groups

\begin{tabular}{|c|c|c|c|c|c|c|c|}
\hline & HR 1.st hour & HR 2.nd hour & HR 3.rd hour & HR 4.th hour & HR 12.th hour & HR 24.th hour & $\mathbf{p}^{1}$ \\
\hline Group 1 & $73.55 \pm 12.21$ & $74.20 \pm 12.71$ & $73.15 \pm 10.22$ & $76.55 \pm 9.09$ & $76.65 \pm 10.09$ & $75.68 \pm 8.91$ & $0.074^{*}$ \\
\hline Group 2 & $79.25 \pm 10.43$ & $77.50 \pm 9.76$ & $80.35 \pm 10.04$ & $81.65 \pm 9.42^{\star *} a$ & $81.25 \pm 7.99$ & $80.28 \pm 7.37$ & $0.981^{*}$ \\
\hline \multirow[t]{3}{*}{ Group 3} & $72.80 \pm 12.20^{*}$ & $74.45 \pm 9.92$ & $72.45 \pm 8.71^{\star}$ & $73.55 \pm 8.70^{\star \star} \mathrm{a}$ & $76.00 \pm 8.15^{*}$ & $75.11 \pm 7.07^{\star}$ & $0.007^{\star}$ \\
\hline & $\mathrm{p} 2=0.131^{\star *}$ & $\mathrm{p} 2=0.509^{* *}$ & $\mathrm{p} 2=0.055^{\star *}$ & $\mathrm{p} 2=0.046^{* *}$ & $\mathrm{p} 2=0.120^{* *}$ & $\mathrm{p} 2=0.133^{* *}$ & \\
\hline & MAP 1.st hour & MAP 2.nd hour & MAP 4.th hour & MAP 6.th hour & MAP12.th hour & MAP24.th hour & \\
\hline Group 1 & $85.10 \pm 12.75$ & $85.20 \pm 13.50$ & $84.85 \pm 11.20^{* *} \mathrm{a}$ & $83.95 \pm 12.30$ & $84.90 \pm 6.72$ & $85.79 \pm 5.76^{\star \star} a$ & $0.745^{\star}$ \\
\hline Group 2 & $92.50 \pm 13.21^{*}$ & $89.10 \pm 11.37^{\star}$ & $90.65 \pm 8.46^{* *} \mathrm{a}$ & $89.20 \pm 7.99$ & $88.10 \pm 8.12^{*}$ & $89.89 \pm 6.16^{*}$ & $0.036^{*}$ \\
\hline \multirow[t]{2}{*}{ Group 3} & $113.90 \pm 131.21^{\star}$ & $87.20 \pm 9.89$ & $87.05 \pm 8.84$ & $83.00 \pm 19.94^{\star}$ & $88.55 \pm 6.21$ & ${ }^{*} 91.53 \pm 6.53^{* *} \mathrm{a}$ & $0.031^{*}$ \\
\hline & $\mathrm{p} 2=0.135^{\star \star}$ & $\mathrm{p} 2=0.333^{\star *}$ & $\mathrm{p} 2=0.058^{\star *}$ & $\mathrm{p} 2=0.062^{\star \star}$ & $\mathrm{p} 2=0.227^{\star \star}$ & $\mathrm{p} 2=0.027^{\star \star}$ & \\
\hline
\end{tabular}




\begin{tabular}{|c|c|c|c|c|c|}
\hline & Group $1(n=20)$ & Group $2(n=20)$ & Group $3(n=20)$ & Total $(n=60)$ & $\mathbf{p}$ \\
\hline Nausea, vomiting $(\mathrm{n}, \%)$ & & & & & $0.020^{*}$ \\
\hline No & $20(100.0 \%)$ & $19(95.0 \%)$ & $15(75.0 \%)$ & $54(90.0 \%)$ & \\
\hline Yes & $0(0.0 \%)$ & $1(5.0 \%)$ & $5(25.0 \%)$ & $6(10.0 \%)$ & \\
\hline Headache $(n, \%)$ & & & & & $0.322^{*}$ \\
\hline No & $19(95.0 \%)$ & $18(90.0 \%)$ & $16(80.0 \%)$ & $53(88.3 \%)$ & \\
\hline Yes & $1(5.0 \%)$ & $2(10.0 \%)$ & $4(20.0 \%)$ & $7(11.7 \%)$ & \\
\hline Hypotension (n,\%) & & & & & $0.596^{*}$ \\
\hline No & $20(100.0 \%)$ & $19(95.0 \%)$ & $19(95.0 \%)$ & $58(96.7 \%)$ & \\
\hline Yes & $0(0.0 \%)$ & $1(5.0 \%)$ & $1(5.0 \%)$ & $2(3.3 \%)$ & \\
\hline Bradycardia (n,\%) & & & & & $0.362^{*}$ \\
\hline No & $20(100.0 \%)$ & $20(100.0 \%)$ & $19(95.0 \%)$ & $59(98.3 \%)$ & \\
\hline Yes & $0(0.0 \%)$ & $0(0.0 \%)$ & $1(5.0 \%)$ & $1(1.7 \%)$ & \\
\hline Urinary retention $(\mathrm{n}, \%)$ & & & & & $0.108^{*}$ \\
\hline No & $20(100.0 \%)$ & $18(90.0 \%)$ & $16(80.0 \%)$ & $54(90.0 \%)$ & \\
\hline Yes & $0(0.0 \%)$ & $2(10.0 \%)$ & $4(20.0 \%)$ & $6(10.0 \%)$ & \\
\hline Total & $68(100 \%)$ & $88(100 \%)$ & $88(100 \%)$ & $156(100 \%)$ & \\
\hline
\end{tabular}

\section{Table 5. Comparison of some descriptive characteristics of the groups}

\begin{tabular}{|lcccc|}
\hline & Group 1 $(\mathbf{n}=\mathbf{2 0})$ & Group 2 $(\mathbf{n}=\mathbf{2 0})$ & Group 3 $(\mathbf{n}=\mathbf{2 0})$ & $\mathbf{p}$ \\
\hline First urination time $(\min )(\mathrm{Mean} \pm \mathrm{Sd})$ & $194.25 \pm 53.63$ & $205.50 \pm 57.42$ & $190.25 \pm 57.86$ & $0.676^{*}$ \\
First analgesic time $(\mathrm{min})(\mathrm{Mean} \pm \mathrm{Sd})$ & $305.40 \pm 143.86^{*}$ & $435.50 \pm 171.70$ & $435.50 \pm 156.08$ & $0.015^{*}$ \\
\hline $\begin{array}{l}* \text { One way ANOVA Test (Post hoc:LSD) } \\
* * \text { Kruskal Wallis Test }\end{array}$ & & & & \\
\hline
\end{tabular}

\section{DISCUSSION}

The anoderm consists of keratinized, stratified squamous epithelium and is extremely sensitive to pain because it has somatic nerve endings. Surgery of benign anorectal diseases such as hemorrhoids, anal fissure, and perianal abscess causes more pain than many other surgical procedures. Postoperative pain is the most common surgical complication of classical hemorrhoidectomy (8).High maximum resting pressure (MRP) values measured by anal manometry reflect the hyperactivity of the anal sphincter muscles and even spasm (9). It has been suggested that this spasm is a cause of severe pain after hemorrhoidectomy (10). The Saddle block we used in this study is effective in reducing anal sphincter tone and controlling postoperative pain.

Direct application of morphine to the intrathecal space provides spinal analgesia. Therefore, intrathecal morphine provides long-term pain relief in the postoperative period $(7,11)$. Uchiyama Ave et al. (8) used $0.05,0.1$ and $0.2 \mathrm{mg}$ of morphine intrathecally in cesarean sections and stated that pain control was better in the group using 0.1 and $0.2 \mathrm{mg}$ morphine compared to the control group without morphine (12). In another study in which 0.1 and $0.2 \mathrm{mg}$ morphine doses were used in cesarean sections, no significant difference was found between the two doses in terms of postoperative analgesia (13). Ozbek et al. (14) found that postoperative analgesic requirement was reduced in patients undergoing (transurethral resection of the prostate) TURP with spinal anesthesia who received 150 $\mu \mathrm{g}$ intrathecal morphine versus those who received 75 $\mu g$ intrathecal morphine. Duman et al. (15) reported that in patients undergoing TURP, intrathecal morphine at a dose of $25 \mu \mathrm{g}$ provides sufficient postoperative analgesia similar to a dose of $50 \mu \mathrm{g}$.In this study, it was observed that the time for the first analgesic requirement in the intrathecal morphine group was approximately two hours longer than the group without morphine. However, there was no difference between the $50 \mu \mathrm{g}$ and $100 \mu \mathrm{g}$ intrathecal morphine groups.

The usefulness of intrathecal morphine is limited at doses more than $300 \mu \mathrm{g}$ due to its side effects (11). These side effects include nausea, vomiting, itching, weakness, urinary retention, delayed type respiratory depression and sedation. We did not experience itching or respiratory depression in any of the patients during this study.

In the study conducted by Baytas (16) on patients who underwent cesarean section, they did not find a significant difference between the groups at the $10^{\text {th }}, 20^{\text {th }}, 30^{\text {th }}, 50^{\text {th }}$, $60^{\text {th }}$ and $70^{\text {th }}$ minutes of the operation in the comparison of the mean blood pressure of the patients according to the groups. They reported higher blood pressure values 
in the $0.1 \mathrm{mg}$ morphine group compared to the $0.05 \mathrm{mg}$ group. In a different study conducted between the groups in which $5 \mu \mathrm{g} / \mathrm{kg}$ intrathecal morphine was used and morphine was not used, no difference was found in terms of hemodynamic parameters (17). In this study, we found no significant difference between the groups in terms of peroperative MAP values. However, in terms of postoperative HR levels, a significant decrease was detected in group 3 in the first 6 hours.

It has been observed that nausea and vomiting, which are among the common postoperative side effects, increase to very high rates when the intrathecal morphine dose exceeds $100 \mu \mathrm{g}$, especially at $200 \mu \mathrm{g}$ levels $(18,19)$. Sakai et al. (20) showed that the use of 50 and $100 \mu \mathrm{g}$ intrathecal morphine in TURP operations created a similar analgesic effect, and the frequency of side effects increased with the use of $100 \mu \mathrm{g}$ morphine, increasing from $23 \%$ to $33 \%$. In our study, in accordance with the literature, although both doses of morphine produced similar analgesic effects, it was observed that nausea and vomiting increased in group 3, where the intrathecal morphine dose was $100 \mu \mathrm{g}$, compared to the other groups. The frequency of nausea was $1 \%$ in Group 2 and 5\% in Group 3, and it was found to be quite low compared to the study of Sakai et al. (20). We believe that the reason for this was the application of saddle spinal anesthesia with hyperbaric bupivacaine in our study, while a sensory block was created reaching T4-T8 levels with tetracaine. With the use of hyperbaric local anesthesia, the saddle spinal anesthesia technique prevents the cephalic spread of intrathecally administered drugs, and the frequency of side effects associated with these drugs decreases. In this way, in perianal surgeries such as hemorrhoidectomy, which is quite painful, the use of strong analgesic morphine together with intrathecal local anesthetics provides effective anesthesia and analgesia. In addition to reducing anal sphincter tone, this method is used by anesthetists especially in anorectal surgeries due to this advantage.

After anorectal surgery, urinary retention may occur due to temporary detrusor muscle dysfunction, secondary urethral spasm, and overhydration (21). It has been shown that it increases with age and the risk is 2.4 times higher in patients over 50 years old. After anorectal surgery, the incidence of postoperative urinary incontinence ranges between $2.3-21.9 \%$ (22).

The hydrophilic nature of morphine delays its systemic uptake resulting in a higher drug concentration in the lumbar region. As a result, while providing better analgesia, it also brings the risk of urinary retention (2123). Moreira et al. (21) investigated the postoperative effects of intrathecal $7 \mathrm{mg}$ of hyperbaric bupivacaine and $80 \mu \mathrm{g}$ of morphine in hemorrhoidectomy surgery. They reported that while better analgesia was provided in the morphine group, $15 \%$ urinary retention developed, and there was no retention in the group without morphine. Similarly, in our study, it was determined that no urinary retention developed in the control group, while it was $10 \%$ in the $50 \mu \mathrm{g}$ morphine group and $20 \%$ in the 100 $\mu \mathrm{g}$ morphine group. It is seen that as the morphine dose increases, the incidence of urinary retention increases depending on the dose.

One of the weak points of this study is the small number of patients. The number of patients was chosen based on the literature. In addition, we believe that it is very valuable since it is a prospective study and the number of studies on intrathecal morphine use in anorectal surgery is limited.

\section{CONCLUSION}

In this study, it was observed that the time for the first analgesic requirement in the groups in which intrathecal morphine was used was approximately two hours longer than the group without morphine. However, there was no difference between the $50 \mu \mathrm{g}$ and $100 \mu \mathrm{g}$ intrathecal morphine groups. In group 3, where the intrathecal morphine dose was $100 \mu \mathrm{g}$, it was observed that nausea and vomiting increased compared to the other groups.It is thought that the use of $50 \mu \mathrm{g}$ of intrathecal morphine in patients undergoing anorectal surgery in saddle block anesthesia has the expected effect on postoperative analgesia and it is considered appropriate to be preferred in anorectal surgery because it causes minimal adverse side effects.

\section{ETHICAL DECLARATIONS}

Ethics Committee Approval: Appropriate Keçiören Training and Research Ethics Committee (IRB) approval has been obtained for the research reported (27.08.2014/651).

Informed Consent: All patients signed the free and informed consent form.

Referee Evaluation Process: Externally peer-reviewed.

Conflict of Interest Statement: The authors have no conflicts of interest to declare.

Financial Disclosure: The authors declared that this study has received no financial support.

Author Contributions: All of the authors declare that they have all participated in the design, execution, and analysis of the paper, and that they have approved the final version.

Acknowledgements: We would like to thank Assoc. Prof. Dr. Esra OZAYAR (Chief of Anesthesiology Clinic, University of Healh Science, Kecioren Training and 
Research Hospital) and Assoc. Prof. Dr. Hakan BULUS (Chief of General Surgery Clinic, University of Healh Science, Kecioren Training and Research Hospital) for permissions and supports in our study. We also thank all the volunteers who participated in our study.

\section{REFERENCES}

1. Sommer M, de Rijke JM, vanKleef M, et al. Theprevalence of postoperativepain in a sample of 1490 surgicalinpatients. Eur J Anaesthesiol 2008; 25: 267-74.

2. Kushwaha R, Hutchings W, Davies C, Rao NG. Randomized clinical trial comparing day-care open haemorrhoidectomy under local versus general anaesthesia. Br J Surg2008; 95: 555-63.

3. Shon YJ, Huh J, Kang SS, Bae SK, Kang RA, Kim DK. Comparison of saddle, lumbar epidural and caudal blocks on anal sphincter tone: A prospective, randomized study. J Int Med Res 2016; 44: 1061-71.

4. Gehling M, Tryba M. Risks and side-effects of inrathecal morphine combined with spinal anaesthesia: A meta-analysis. Anaesthesia 2008; 64: 643-51.

5. Pöpping DM, Elia N, Marret E, Wenk M, Tramèr MR. Opioids added to local anesthetics for single-shot intrathecal anesthesia in patients undergoing minor surgery: A meta-analysis of randomized trials. Pain 2012; 153: 784-93.

6. Karaman S, Günüsen I, Uyar M, Biricik E, Frrat V. The effects of morphine and fentanyl alone or in combination added to intrathecal bupivacaine in spinal anesthesia for cesarean section. Agr1 2011; 23: 57-63.

7. Meylan N, Elia N, Lysakowski C, Tramer MR. Benefit and risk of intrathecal morphine without local anaesthetic in patients undergoing mojor surgery: Meta-analysis of randomized trials. Br J Anaesth 2009; 102: 156-67.

8. Jayaraman S, Colquhoun PHD, Malthaner RA. Stapled hemorrhoidopexy is associated with a higher long-term recurrence rate of internal hemorrhoids compared with conventional excisional hemorrhoid surgery. Dis Colon Rectum 2007; 50: 1297-305.

9. Hancock B. Lord's procedure for haemorrhoids: a prospective anal pressure study. Br J Surg 1981; 68: 72930

10. Fueglistaler P, Guenin MO, Montali I, et al. Long-term results after stapled hemorrhoidopexy: high patient satisfaction despite frequent postoperative symptoms. Dis Colon Rectum 2007; 50: 204-12.

11. Rathmell JP, Lair TR, Nauman B: The role of intrathecal drugs in the treatment of acute pain. Anesth Analg 2005; 101: 30-43.

12. Uchiyama A, Nakano S, Ueyama H, Nishimura M, Tashiro C. Low dose intrathecal morphine and pain relief following caesarean section. Int J Obstet Anesth 1994; 3: 87-91.

13. Milner AR, Bogod DG, Harwood RJ. Intrathecal administration of morphine for elective Caesarean section. A comparison between $0.1 \mathrm{mg}$ and $0.2 \mathrm{mg}$. Anaesthesia 1996; 51: 871-3.

14. Ozbek H, Deniz MN, Erakgun A, Erhan E. Comparison of 75 and $150 \mu \mathrm{g}$ doses of intrathecal morphine for postoperative analgesia after transurethral resection of the prostate under spinal anesthesia. J Opioid Manag2013; 9: 415-20.

15. Duman A, Apiliogullari S, Balasar M, Gürbüz R, Karcioglu M.Comparison of $50 \mathrm{~g}$ and $25 \mathrm{~g}$ doses of intrathecal morphine on postoperative analgesic requirements in patients undergoing transurethral resection of the prostate with intrathecal anesthesia. J Clin Anesth 2010; 22: 329-33.

16. Baytas V. Sezaryen için spinal anestezide, kullanılan local anesteziğe eklenen iki farklı morfin dozunun kontrol grubu ile karşılaştırılarak değerlendirilmesi. Ankara University Medical School, Department of Anesthesiology and Reanimation, 2010. (Thesis, in Turkish)
17. Karaman S, Kocabas S, Uyar M, Zincircioglu C, Firat V. Intrathecal morphine: effects on perioperative hemodynamics, postoperative analgesia, and stress response for total abdominal hysterectomy. Adv Ther 2006; 23: 295-306.

18. Kirson LE, Goldman JM, Slover RB. Low-dose intrathecal morphine for postoperative pain control in patients undergoing transurethral resection of the prostate. Anesthesiology 1989; 71: 192-5.

19. Incesu A, Deniz MN, Elvan E, Ugur G. TheEfficacy of Intrathecal Morphine With Bupivacaine For Postoperative Analgesia After TUR-B.CBU-SBED 2020; 7: 65-9.

20. Sakai T, Use T, Shimamoto H, Use T, Shimamoto H, Fukano T, Sumikawa K. Mini-dose $(0.05 \mathrm{mg})$ intrathecal morphine provides effective analgesia after transurethral resection of the prostate. Can J Anaesth 2003; 50: 1027-30.

21. MoreiraM, Moreira JP, Isaac RR, et al. Morphinespinal block anesthesia in patients who undergo an open hemorrhoidectomy: a prospective analysis of pain control and postoperative complications. AnnColoproctol 2014; 30: 135-40.

22. Toyonaga T1, Sogawa MN, Jiang SF,et al. Postoperative urinary retention after surgery for benign anorectal disease: potential risk factors and strategy for prevention. Int J Colorectal Dis 2006; 21 : 676-82.

23. Darrah DM, Griebling TL, Silverstein JH. Postoperative urinary retention. Anesthesiol Clin 2009; 27: 465-84.

24. Prasad ML, Abcarian H. Urinary retention following operations for benign anorectal diseases. Dis Colon Rectum 1978; 21: 490-2. 